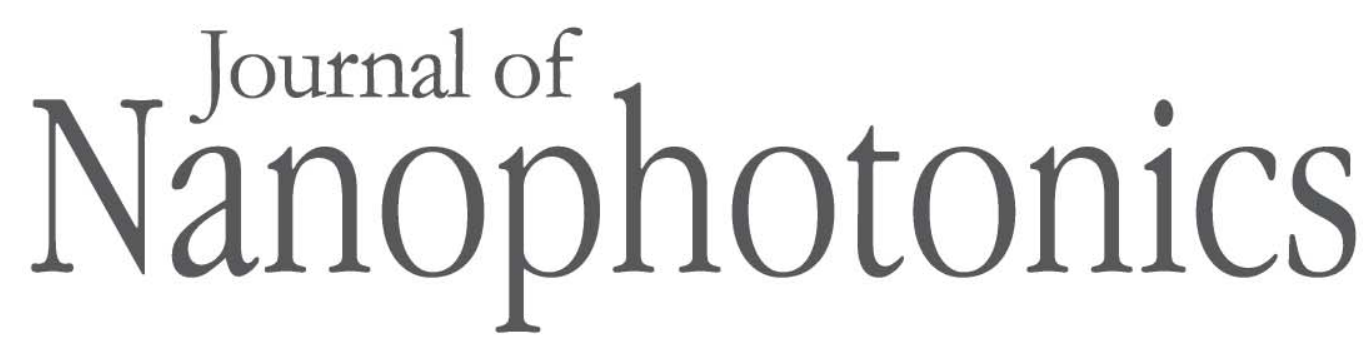

SPIEDigitalLibrary.org/jnp

\title{
In-situ monitoring of the growth of nanostructured aluminum thin film
}

Michal Novotny

Jiri Bulir

Jan Lancok

Petr Pokorny

Michal Bodnar 


\title{
In-situ monitoring of the growth of nanostructured aluminum thin film
}

\author{
Michal Novotny, Jiri Bulir, Jan Lancok, Petr Pokorny, and Michal Bodnar \\ Institute of Physics of the ASCR, v.v.i., Na Slovance 2, 182 21, Prague, Czech Republic \\ novotnym@fzu.cz
}

\begin{abstract}
Metal thin film functional properties depend strongly on its nanostructure, which can be manipulated by varying nucleation and growth conditions. Hence, in order to control the nanostructure of aluminum thin films fabricated by RF magnetron sputtering, we made use of in-situ monitoring of electrical and optical properties of the growing layer as well as plasma characterization by mass and optical emission spectroscopy. The electrical conductivity and I-V characteristics were measured. The optical constants were obtained from optical monitoring based on spectral ellipsometry. The relevant models (based on one or two Lorentz oscillators and B-spline functions) were suggested to evaluate the data obtained from the monitoring techniques. The results of the in-situ monitoring were correlated with scanning electron microscope analyses. We demonstrated the monitoring was able to distinguish the growth mode in real-time. We could estimate the percolation threshold of the growing layer and control layer nanostructure. The nanostructure was effectively manipulated by RF power variation. Optical functions exhibiting plasmonic behavior in the UV range and a strong nonlinear character of $\mathrm{I}-\mathrm{V}$ curves were obtained for an ultrathin Al film deposited at a lower growth rate. ( 2011 Society of Photo-Optical Instrumentation Engineers (SPIE). [DOI: 10.1117/1.3543816]
\end{abstract}

Keywords: aluminum ultrathin film; magnetron sputtering; in-situ monitoring; electrical conductivity; spectral ellipsometry; optical emission spectroscopy; mass spectroscopy.

Paper 10069SSPR received Oct. 1, 2010; revised manuscript received Nov. 23, 2010; accepted for publication Nov. 24, 2010; published online Feb. 3, 2011; corrected Mar. 3, 2011.

\section{Introduction}

Nanostructured (particulate) aluminum (Al) thin films have been recently shown as potential substrates for metal-enhanced fluorescence (MEF) in the ultraviolet-blue spectral region, ${ }^{1-3}$ where fluorophores in the excited state undergo near-field interactions with the metal particles to create surface plasmons (SPS). Thin Al films make it possible to observe SP-coupled emission at UV wavelengths, while silver or gold thin films can be used at visible wavelengths only. The fluorescence enhancement factor depends on the thickness of the Al films as the size of the nanostructures formed varies with $\mathrm{Al}$ thickness. ${ }^{2}$ Thin $\mathrm{Al}$ films have also played an important role in modern microelectronics, i.e., integrated circuits (IC). This has been the most widely used interconnection material in IC devices ${ }^{4}$ because of its low resistivity and its ability to form ohmic contact with Si-based semiconductors. Thin Al films for such devices are commonly fabricated by sputtering (in particular magnetron sputtering that allows aluminum to be deposited at high deposition rates of up to $1 \mu \mathrm{m} / \mathrm{min}$ ). This application requires forming a continuous film in the initial stage of the growth process.

The experimental consequences of nucleation and growth play an extremely important role in determining the structure and characteristics of thin films. The film growth process for aluminum can be divided into three different stages: nucleation, coalescence and channel. The metal grains in the films grow during the whole process, therefore the volume fraction of metal grain increases with the film thickness. The dependence of electrical ${ }^{5}$ and optical ${ }^{6,7}$ properties on the thickness

$1934-2608 / 2011 / \$ 25.00$ @ 2011 SPIE 
of ultrathin $\mathrm{Al}$ films is believed to come from microstructure transition during the film growth. dc conductivity of ultrathin $\mathrm{Al}$ films (film thickness of $100 \mathrm{~nm}) \sigma \sim 10^{6} \Omega^{-1} \mathrm{~m}^{-1}\left(\rho \sim 10^{-6} \Omega \mathrm{m}\right)^{5}$ was found to be much lower than that of bulk aluminum $\sigma=3.8 \times 10^{7} \Omega^{-1} \mathrm{~m}^{-1}\left(\rho=2.6 \times 10^{-8}\right.$ $\Omega \mathrm{m}) .{ }^{8}$ This fact can be attributed to scattering of electrons by surfaces and grain boundaries in the film. However, simple dc conductivity measurements are not sufficient to understand the conduction mechanism in the ultrathin film, where quantum mechanical tunneling plays a role. ${ }^{9}$ Other characterizations, i.e., I-V characteristics or temperature dependence, must be analyzed. Optical functions of ultrathin $\mathrm{Al}$ films were determined using spectrophotometric measurements ${ }^{5}$ or spectral ellipsometry (SE). ${ }^{7}$ The SE was demonstrated as a valuable technique for real-time monitoring of the evolution of the optical functions of Al film throughout all stages of the growth process by thermal evaporation on c-Si substrate. ${ }^{7}$ The $\mathrm{Al}$ film growth in a magnetron sputtering system depends critically on the characteristics of the plasma in the vicinity of the substrate, which is closely related to deposition conditions. ${ }^{10}$ It is important to utilize plasma diagnostics, e.g., mass spectroscopy ${ }^{11-14}$ and optical emission spectroscopy ${ }^{13,15}$ to better understand plasma processes taking place near the substrate and magnetron target, and effectively control the deposition process.

Hence, in order to understand and control the $\mathrm{Al}$ film growth process in real time, one has to employ several in-situ monitoring techniques, i.e., monitoring of electrical and optical properties, and plasma characterizations, too.

We report, in this paper, a complex in-situ monitoring of electrical conductivity (I-V characteristics) and optical functions of the growing $\mathrm{Al}$ layer as well as plasma characterization by mass and optical emission spectroscopy. The results of the in-situ monitoring are correlated with scanning electron microscope (SEM) analyses.

\section{Experimental}

Ultrathin Al films were grown by RF magnetron sputtering in a stainless steel chamber. The chamber was pumped down by turbomolecular pump to a pressure of $2 \times 10^{-4} \mathrm{~Pa}$. A round shape magnetron aluminum target (Al purity of 99.99\%) of $100 \mathrm{~mm}$ diameter was used for sputtering. The magnetron discharge was maintained in Ar atmosphere at constant pressure of $2 \mathrm{~Pa}$ and at RF magnetron power $\left(\mathrm{P}_{\mathrm{RF}}\right)$ of either 50 or $200 \mathrm{~W}$. Single-side polished fused silica substrates of dimension $15 \times 15 \mathrm{~mm}^{2}$ were used for film deposition at room temperature. The distance between the target and the substrate was $100 \mathrm{~mm}$.

The sample was electrically contacted using four wires onto two silver electrodes of rectangular shape with dimension of $2.5 \times 15 \mathrm{~mm}^{2}$. The electrodes were sputtered along two sides of the substrate. The substrate holder with the sample is shown in Fig. 1(a). In-situ monitoring of electrical properties was performed using a multimeter Agilent 34411A and ac-dc current source Keithley 6221. The measurement setup is schematically shown in Fig. 1(b).

In-situ monitoring of optical properties of the growing film was performed using a spectral ellipsometer (J.A.Wollam M2000) equipped with a software package CompleteEASE ${ }^{\circledR}$ for data acquisition and analysis. The ellipsometer was attached to the deposition chamber at an incident angle of $76.5 \mathrm{deg}$. Real-time optical measurements were taken in the wavelength region from 250 to $1000 \mathrm{~nm}$, at a sampling rate of $10 \mathrm{~Hz}$. Optical functions - refractive index $(n)$ and extinction coefficient $(k)$-were derived using an appropriate model to fit the measured spectral ellipsometric data. The model was based on parallel layers on a semi-infinite substrate. We assume smooth interfaces and homogeneous optical constants in the model in order to simplify the task and minimize the number of fitted parameters.

Plasma mass spectroscopy was performed using a mass spectrometer EQP 500 HIDEN Analytical, Ltd. Plasma flew into the spectrometer through an orifice $200 \mu \mathrm{m}$ in diameter placed at a distance of $100 \mathrm{~mm}$ from the magnetron target. Mass spectra were taken in the range from $\mathrm{m} / \mathrm{q}=1$ to $\mathrm{m} / \mathrm{q}=100 \mathrm{amu}$ with a resolution of $0.5 \mathrm{amu}$.

The system for plasma characterization by optical emission spectroscopy was based on a monochromator Triax iHR550 equipped with a grating 1200 or $2400 \mathrm{~g} / \mathrm{mm}$ and liquid nitrogen 


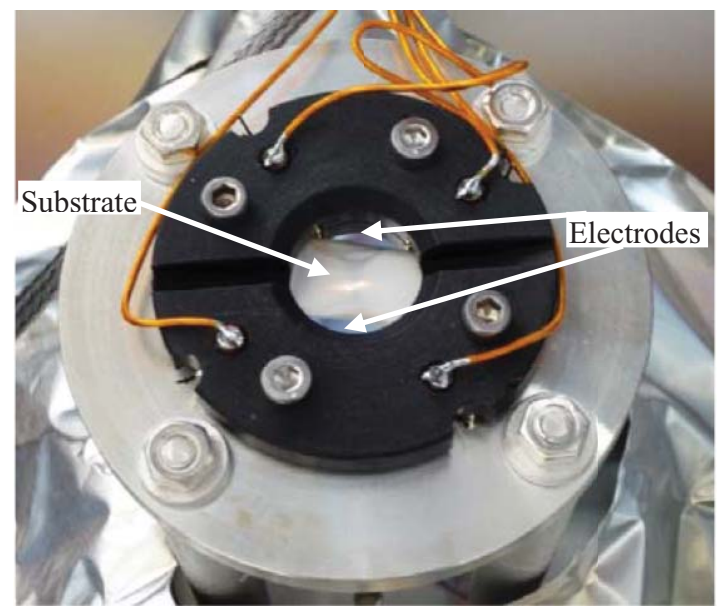

(a)

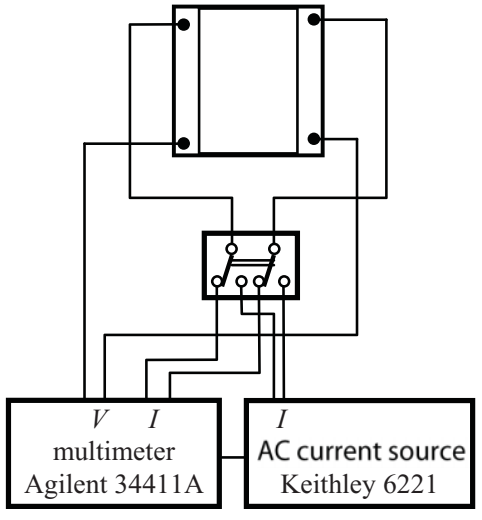

(b)

Fig. 1 (a) A substrate with electrodes placed in the substrate holder for in-situ simultaneous monitoring of electrical and optical properties.(b) Scheme of electrical properties measurements.

cooled CCD camera Symphony $(2048 \times 512$ pixels). The OES signal was collected perpendicular to the magnetron-substrate axis by a focusing lens and optical fiber. The spectra were taken at the magnetron target and substrate holder. Spectra were analyzed in the wavelength region from 350 to $750 \mathrm{~nm}$ with a resolution of $0.05 \mathrm{~nm}$.

Morphology and microstructural properties were analyzed by means of SEM JEOL JSM7500F. The film thickness was measured with a profilometer.

\section{Results and Discussion}

We first realized detailed characterizations of magnetron plasma by mass spectroscopy and optical emission spectroscopy. These analyses revealed plasma composition and properties in the substrate vicinity as well as near the magnetron target. In the next step we performed several calibration measurements to estimate the film growth rate. We obtained a growth rate of $0.45 \mathrm{~nm} \mathrm{~s}^{-1}$ and $0.12 \mathrm{~nm} \mathrm{~s}^{-1}$ for the films deposited at RF power of 200 and $50 \mathrm{~W}$, respectively. Then we proceeded with the deposition of Al thin film and in-situ characterization of optical and electrical properties of the growing film.

\subsection{Plasma Characterization}

The mass spectrum of ions and ionized radicals generated in the magnetron discharge in magnetron plasma is displayed in Fig. 2. The spectrum is composed of single ionized atoms $\mathrm{Al}^{+}$ $(\mathrm{m} / \mathrm{q}=27 \mathrm{amu}), \mathrm{Ar}^{+}(\mathrm{m} / \mathrm{q}=40 \mathrm{amu}), \mathrm{Al}_{2}{ }^{+}(\mathrm{m} / \mathrm{q}=54), \mathrm{Ar}_{2}{ }^{+}(\mathrm{m} / \mathrm{q}=80 \mathrm{amu})$, doubly ionized atoms $\mathrm{Al}^{2+}(\mathrm{m} / \mathrm{q}=13.5 \mathrm{amu}), \mathrm{Ar}_{2}{ }^{2+}(\mathrm{m} / \mathrm{q}=20 \mathrm{amu})$, and ionized radical $\mathrm{AlAr}^{+}$ $(\mathrm{m} / \mathrm{q}=67 \mathrm{amu})$. We also detected low signals of ${ }^{36} \mathrm{Ar}^{+}$and ${ }^{38} \mathrm{Ar}^{+}$isotope ions and $\mathrm{H}^{+}, \mathrm{H}_{2}{ }^{+}$, $\mathrm{H}_{2} \mathrm{O}^{+}$, and $\mathrm{N}_{2}{ }^{+}$ions from residual atmosphere. Let us note that neither $\mathrm{O}$ nor $\mathrm{O}_{2}{ }^{+}$oxygen species were recorded in the mass spectra of magnetron discharge plasma. This fact is of great importance regarding the prevention of undesirable oxidation processes of the Al thin film during the growth.

Characteristic OES spectra of magnetron plasma taken in the wavelength region from 350 to $750 \mathrm{~nm}$ at the magnetron target and at the substrate are shown in Fig. 3. The intensities of neutral $\mathrm{Al}^{*}$ emission lines at 394.4 and $396.15 \mathrm{~nm}$ dominate the OES spectra taken at the target. $\mathrm{Al}^{*}$ emission lines of much lower intensity were also detected in the OES spectra taken at the 
Novotny et al.: In-situ monitoring of the growth of a nanostructured aluminum thin film

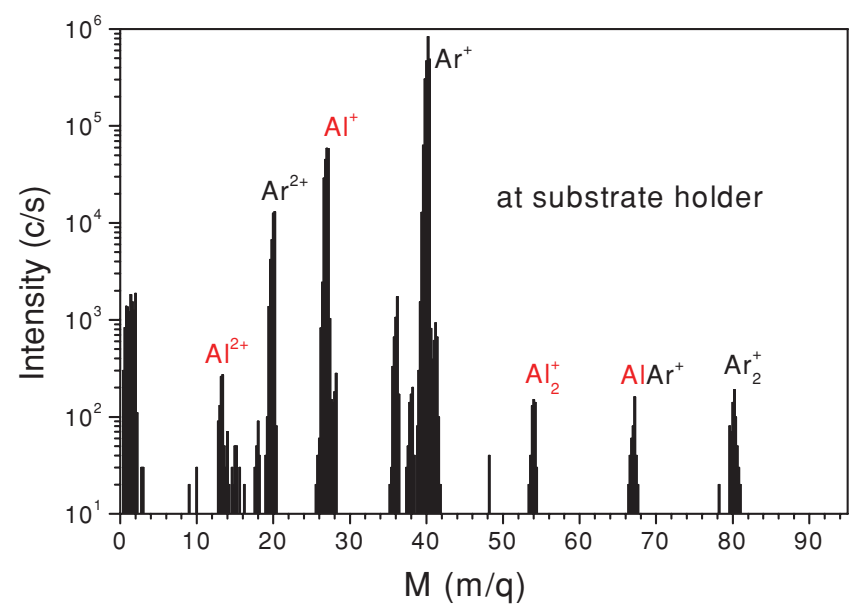

Fig. 2 Mass spectra of ions and ionized radicals occurring in the magnetron discharge plasma in the vicinity of the substrate.

substrate. The other lines appearing in the spectra in Fig. 3 can be assigned to neutral Ar. A few weak $\mathrm{Ar}^{+}$lines can also be recognized in the spectra. The upper levels of $\mathrm{Ar}$ (all well above $10 \mathrm{eV}$ ) can be populated in different ways, i.e., predominantly by direct electron impact from the ground state, from metastable states and from cascades from higher states. ${ }^{13}$ The minimum excitation energy of aluminum is much lower (around $3.15 \mathrm{eV}$ ). Hence a different group of electrons might contribute to $\mathrm{Al}$ excitation.

\subsection{In-Situ Monitoring of Optical Properties}

Evolution of the ellipsometric angles ( $\Psi$ and $\Delta$ ), in the spectral region from 250 to $1000 \mathrm{~nm}$, measured during $\mathrm{Al}$ thin film growth (at $\mathrm{P}_{\mathrm{RF}}=200 \mathrm{~W}$ ), is shown in Fig. 4. The optical functions $(n$ and $k$ ) derived from these SE data are depicted in Fig. 5. The SE data revealed a substantial change of the optical properties of the $\mathrm{Al}$ film at nucleation and coalescence
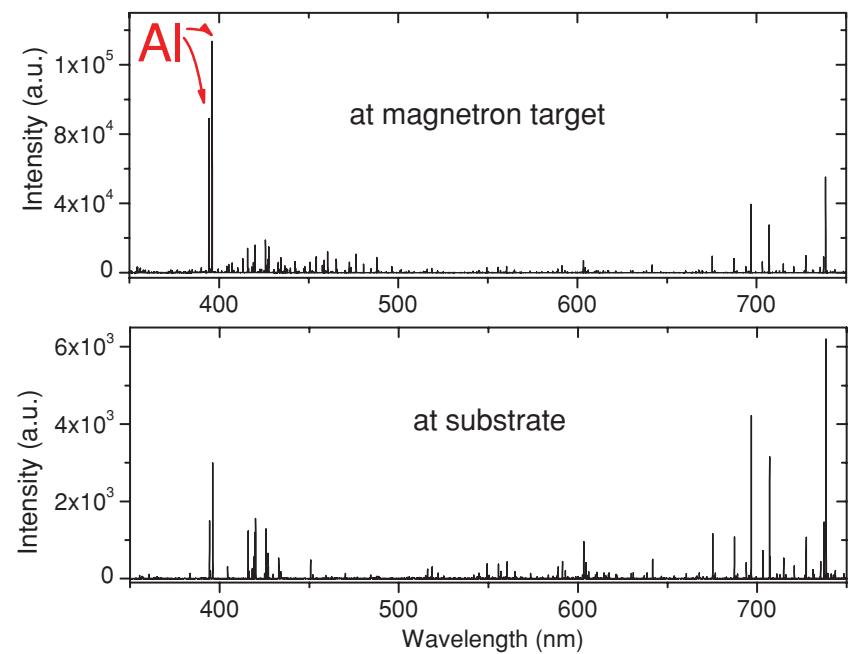

Fig. 3 Optical emission spectra of plasma generated by the magnetron discharge. The spectra were taken in the vicinity of the magnetron target and the substrate. 
Novotny et al.: In-situ monitoring of the growth of a nanostructured aluminum thin film

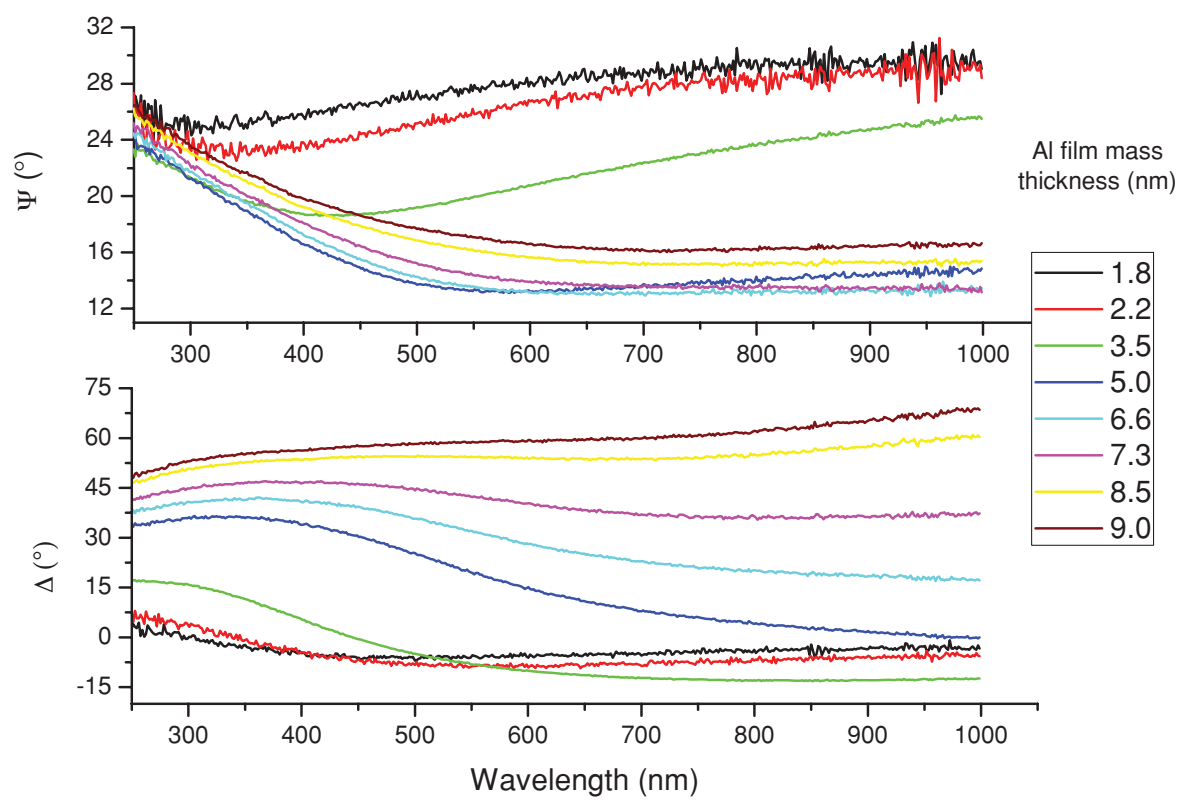

Fig. 4 Ellipsometric angles ( $\Psi$ and $\Delta$ ) of the Al thin film at different growth stages.

stages that correspond to film mass thickness from 2.2 to $5 \mathrm{~nm}$. At these stages, the SE data could be successfully fitted using a dispersion model based on two Lorentz oscillators, which describes well the resonant character of the dispersion curve. ${ }^{16}$ The resonant character indicates noncontinuous growth and nanoislands formation of $\mathrm{Al}$ at initial stages of the growth process. We can clearly observe plasmonic behavior at these films in the UV-blue spectral range, when we follow the development of the extinction coefficient $(k)$ shown in Fig. 5.

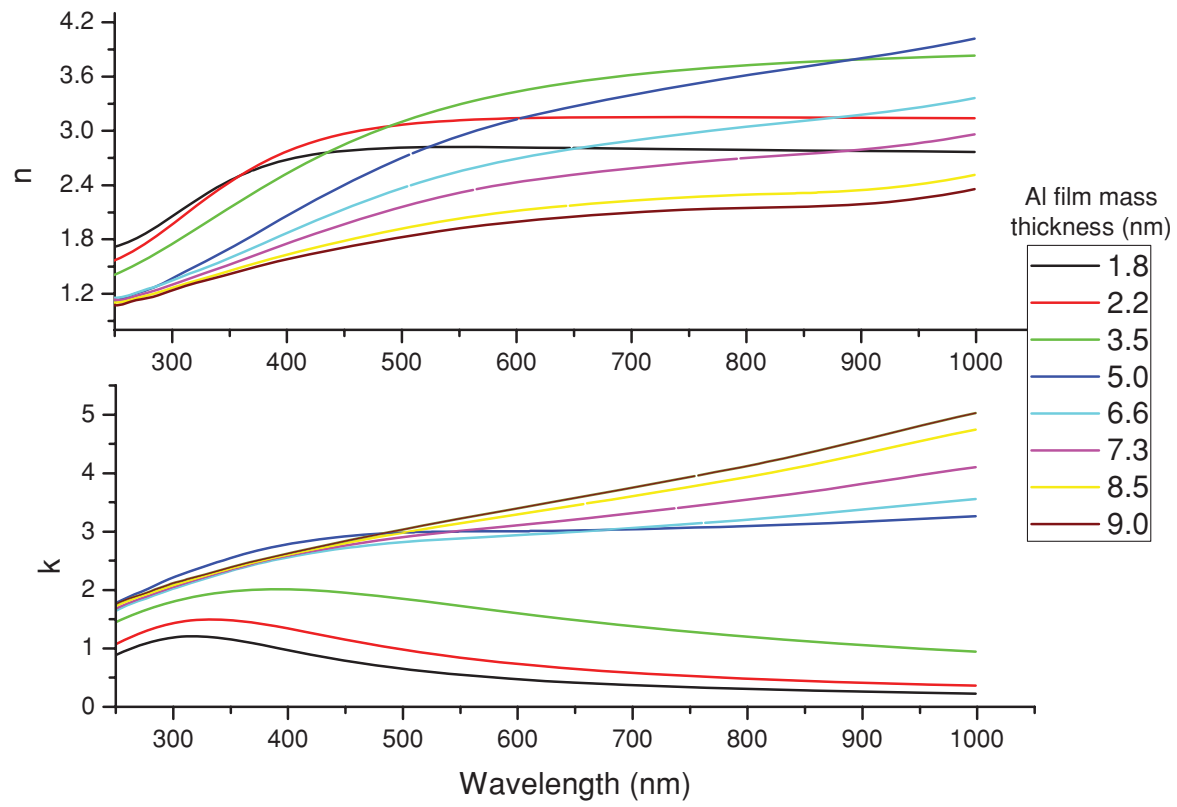

Fig. 5 Optical functions ( $n$ and $k$ ) of the Al thin film at different growth stages. 
Novotny et al.: In-situ monitoring of the growth of a nanostructured aluminum thin film

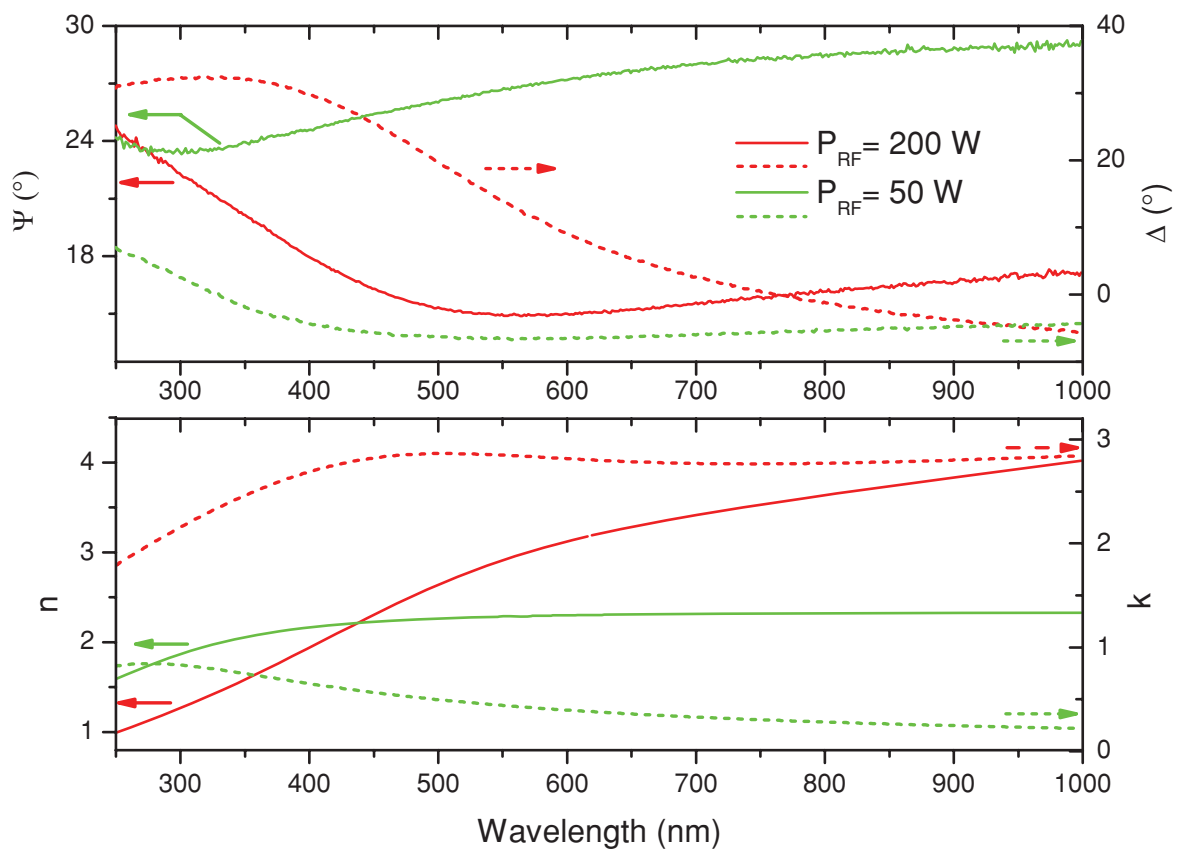

Fig. 6 Ellipsometric angles ( $\Psi$ and $\Delta$ ) and optical functions ( $n$ and $k$ ) of Al ultrathin films of mass thickness of $d \sim 4.5 \mathrm{~nm}$ and $d \sim 4.7 \mathrm{~nm}$ prepared at $\mathrm{P}_{\mathrm{RF}}=200 \mathrm{~W}$ and $\mathrm{P}_{\mathrm{RF}}=50 \mathrm{~W}$, respectively.

The observed plasmon resonance peak in the extinction coefficient shifts from $\lambda=320 \mathrm{~nm}$ to $\lambda=390 \mathrm{~nm}$ and simultaneously the value of $k$ maximum increases from 1.2 to 2 as the growth of the layer proceeds and mass thickness increases from $d \sim 1.8 \mathrm{~nm}$ to $d \sim 3.5 \mathrm{~nm}$. The SE measurements taken around and above the Al film percolation threshold $(d \sim 5 \mathrm{~nm})$ revealed further dramatic changes in the optical properties of the film, compared to the films at the coalescence stage. The SE data in this stage could not be any longer fitted using the model of two Lorentz oscillators. For a mathematical description of general behavior of the dispersion curves in this case, we used B-spline functions, which successfully fitted the SE data. The B-splines were demonstrated as a useful numerical tool for parameterization of the dispersion curve of general SE data. ${ }^{17} \mathrm{~A}$ set of these basis functions used in CompleteEASE ${ }^{\circledR}$ can describe complex structure in the absorption spectra, while simultaneously providing the physically correct (i.e., Kramers-Kronig consistent) dispersion spectra. ${ }^{17} \mathrm{~B}$-splines degree of 3 was used and the knot spacing was optimized with respect of the goodness of the fit. The plasmon peak vanishes at $d \sim 5 \mathrm{~nm}$ and $k$ becomes an ascending function of $\lambda$ at $d>$ $6.6 \mathrm{~nm}$.

The influence of lower RF power (resulting in lower growth rate) on optical properties of the deposited film can be observed in Fig. 6, where the measured SE data and optical functions of the films of equivalent mass thickness $d \sim 4.5 \mathrm{~nm}$ and $d \sim 4.7 \mathrm{~nm}$ prepared at $\mathrm{P}_{\mathrm{RF}}=200 \mathrm{~W}$ and $\mathrm{P}_{\mathrm{RF}}=50 \mathrm{~W}$, respectively, are compared. The SE data of the film deposited at $\mathrm{P}_{\mathrm{RF}}=50 \mathrm{~W}$ could be fitted using a model of only one Lorentz oscillator, while two Lorentz oscillators had to be applied for the film prepared at $\mathrm{P}_{\mathrm{RF}}=200 \mathrm{~W}$ in order to correct the fit. We can observe different behavior related to localised plasmon, when the plasmon peak is located at $\lambda=260 \mathrm{~nm}\left(\right.$ at $\left.\mathrm{P}_{\mathrm{RF}}=50 \mathrm{~W}\right)$ and $\lambda=400 \mathrm{~nm}\left(\right.$ at $\left.\mathrm{P}_{\mathrm{RF}}=200 \mathrm{~W}\right)$. The plasmon peak position at $\lambda=260 \mathrm{~nm}$ obtained for the sample prepared at $\mathrm{P}_{\mathrm{RF}}=50 \mathrm{~W}(d \sim 4.7 \mathrm{~nm})$, whose optical functions are shown in Fig. 6, is even lower than that observed in thinner films of $d \sim 2 \mathrm{~nm}$ and $d \sim 3.5 \mathrm{~nm}$ prepared at $\mathrm{P}_{\mathrm{RF}}=200 \mathrm{~W}$, whose optical functions are shown in Fig. 5. This observation suggests a discrepant nature of the nanostructure films prepared at $\mathrm{P}_{\mathrm{RF}}=50 \mathrm{~W}$ and $\mathrm{P}_{\mathrm{RF}}=200 \mathrm{~W}$. 


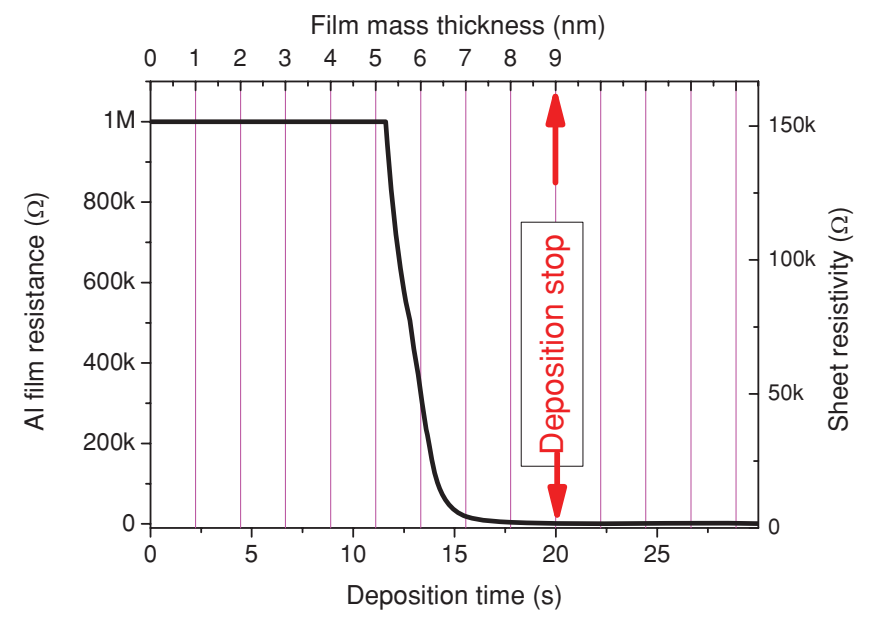

Fig. 7 Evolution of electrical resistance of Al thin film during the growth. Final film mass thickness $d \sim 9 \mathrm{~nm}$ and resistance $\sim 205 \Omega$.

\subsection{In-Situ Monitoring of Electrical Properties}

The evolution of electrical resistance and sheet resistivity of the same sample, whose SE data and optical functions are shown in Figs. 4 and 5, respectively, was simultaneously measured during the growth. The electrical properties of the sample are shown in Fig. 7. We were not able to monitor the film resistance when it exceeded $1 \mathrm{M} \Omega$ (at the beginning of the deposition, in this case within the first $11 \mathrm{~s}$ ) because the plasma conductivity has significantly affected these measurements. The resistance of $205 \Omega$ was obtained in the final film of mass thickness $d \sim 9 \mathrm{~nm}$. The obtained resistance is much higher than that of the bulk sample of equivalent mass thickness, which would be $2 \Omega$. This difference is due to electron scattering on surface grains, which plays a dominant role in thin films. ${ }^{18}$

In order to explain resistivity behavior of the obtained $\mathrm{Al}$ ultrathin films, other effects and conduction mechanism, i.e., quantum tunnelling and thermionic emission, must be considered. ${ }^{9}$ We observed nonlinear I-V curves in ultrathin films with $d<10 \mathrm{~nm}$, which can be attributed to these effects. The I-V curve nonlinearity was exceedingly pronounced for the film of $d \sim 4.7 \mathrm{~nm}$ prepared at $\mathrm{P}_{\mathrm{RF}}=50 \mathrm{~W}$, as can be seen in Fig. 8, where the I-V curves measured for films prepared at $\mathrm{P}_{\mathrm{RF}}=50 \mathrm{~W}$ and $\mathrm{P}_{\mathrm{RF}}=200 \mathrm{~W}$ are displayed. The obtained optical

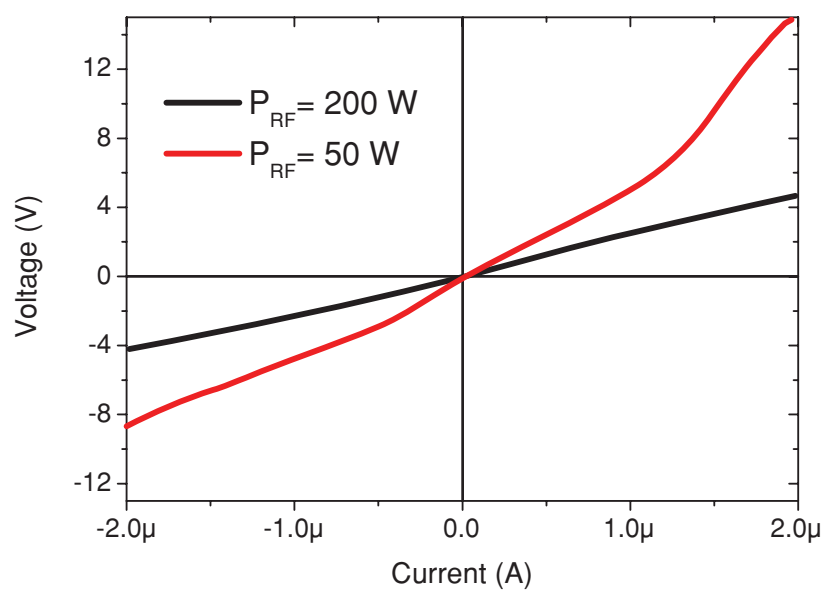

Fig. $8 \mathrm{I}-\mathrm{V}$ curve measured in Al ultrathin films of mass thickness of $d \sim 4.5 \mathrm{~nm}$ and $d \sim 4.7 \mathrm{~nm}$ prepared at $\mathrm{P}_{\mathrm{RF}}=200 \mathrm{~W}$ and $\mathrm{P}_{\mathrm{RF}}=50 \mathrm{~W}$, respectively. 

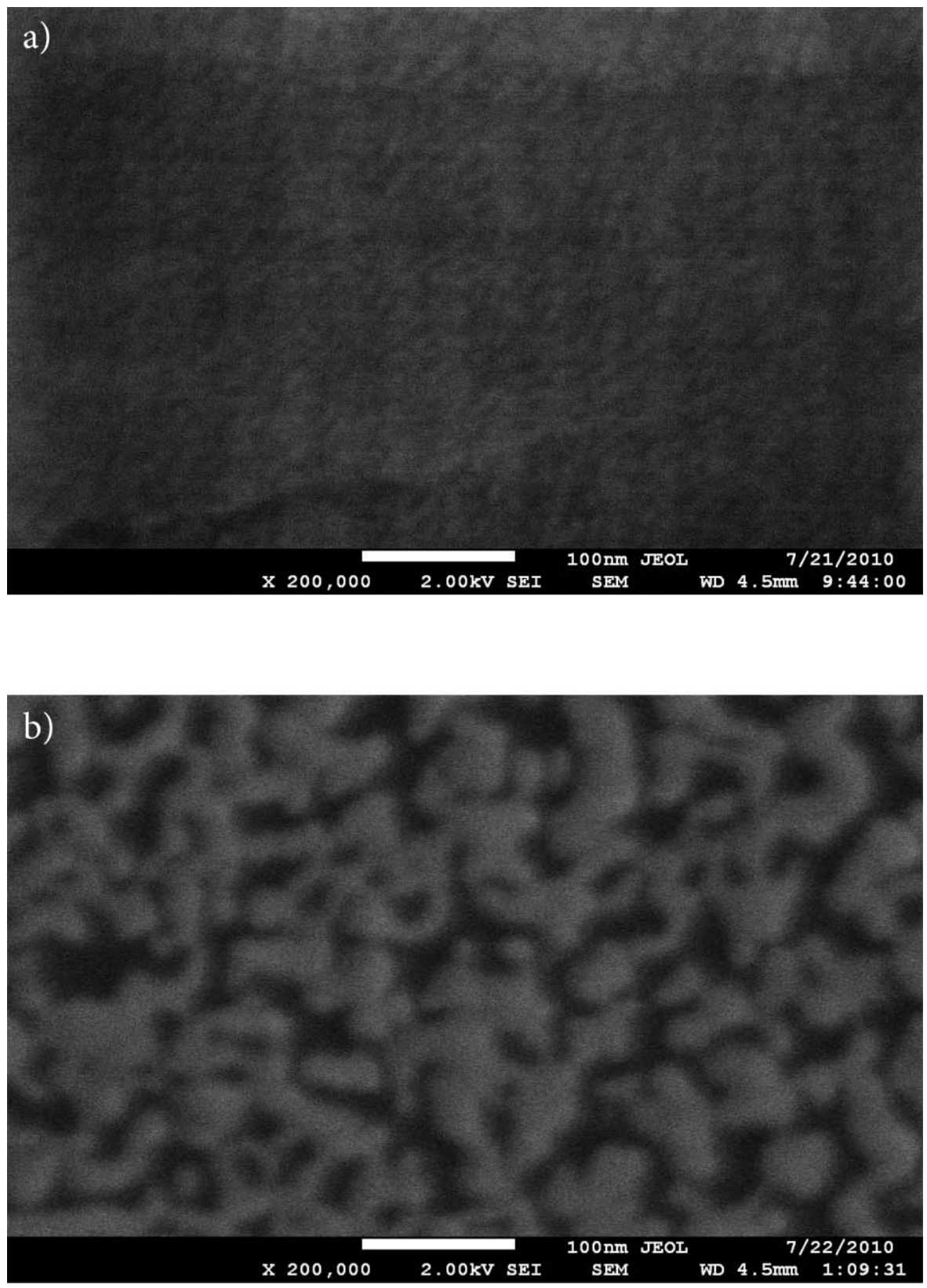

Fig. 9 Morphology of Al ultrathin film prepared at: (a) $\mathrm{P}_{\mathrm{RF}}=200 \mathrm{~W}$ (mass thickness of $d \sim 4.5 \mathrm{~nm}$ ) and (b) $\mathrm{P}_{\mathrm{RF}}=50 \mathrm{~W}$ (mass thickness of $d \sim 4.7 \mathrm{~nm}$ ).

(Fig. 6) and electrical (Fig. 8) properties accordingly suggest that the nanostructure of the film deposited at $\mathrm{P}_{\mathrm{RF}}=50 \mathrm{~W}$ and that deposited at $\mathrm{P}_{\mathrm{RF}}=200 \mathrm{~W}$ must be different.

\subsection{Morphology and Microstructural properties}

The dependence of Al film morphology on the film mass thickness from $d \sim 4.5 \mathrm{~nm}$ to $d \sim 200 \mathrm{~nm}$ for films prepared at $\mathrm{P}_{\mathrm{RF}}=200 \mathrm{~W}$ revealed increasing grain size from 10 to $100 \mathrm{~nm}$. The surface of the film of $d \sim 4.5 \mathrm{~nm}$, shown in Fig. 9 was found semicontinuous, while that of the films of $d>9 \mathrm{~nm}$ prepared at the same deposition rate exhibited 
continuous character. We found a very different morphology of Al ultrathin films of comparable mass thicknesses deposited at $\mathrm{P}_{\mathrm{RF}}=200 \mathrm{~W}(d \sim 4.5 \mathrm{~nm})$ and $\mathrm{P}_{\mathrm{RF}}=50 \mathrm{~W}(d \sim 4.7 \mathrm{~nm})$, whose SEM images are shown in Fig. 9. The film prepared at $\mathrm{P}_{\mathrm{RF}}=50 \mathrm{~W}$ (growth rate of $0.12 \mathrm{~nm}$ $\mathrm{s}^{-1}$ ) shown in Fig. 9(b) exhibited semicontinuous structure with particulates of irregular shape with an average size of $50 \mathrm{~nm}$. Substantial differences of nanostructure of the film deposited at $\mathrm{P}_{\mathrm{RF}}=200 \mathrm{~W}$ and $\mathrm{P}_{\mathrm{RF}}=50 \mathrm{~W}$, observed in Figs. 9(a) and 9(b), respectively, explain the discrepancy in the optical properties (shown in Fig. 6) and electrical properties (nonlinear I-V curve presented in Fig. 8) of the film deposited at high and low growth rate.

At a high growth rate $\left(0.45 \mathrm{~nm} \mathrm{~s}^{-1}\right.$ at $\left.\mathrm{P}_{\mathrm{RF}}=200 \mathrm{~W}\right)$ the film growth stays in the nucleation stage, i.e., a high nucleation density, and a continuous film in an earlier stage was observed. During the nucleation stage, the growth parallel to the substrate exceeds the growth normal to the substrate, while the opposite is true during the coalescence stage. The tendency to form nanoparticulated semicontinuous $\mathrm{Al}$ film is also enhanced by low deposition temperature, i.e., room temperature, when the nuclei do not possess enough energy to move along the surface and need a longer time to coalesce with other nuclei into islands.

\section{Conclusion}

The growth processes of nanostructured aluminum thin films in a RF magnetron sputtering deposition system were in-situ characterized by mass spectroscopy, optical emission spectroscopy, spectral ellipsometry, and electrical measurements. Magnetron plasma, in the vicinity of the substrate, contains aluminum ions $\mathrm{Al}^{+}, \mathrm{Al}^{2+}, \mathrm{Al}_{2}{ }^{+}$, argon ions $\mathrm{Ar}^{+}, \mathrm{Ar}^{2+}, \mathrm{Ar}_{2}{ }^{+}$and radicals $\mathrm{AlAr}^{+}$as well as excited aluminum atoms $\mathrm{Al}^{*}$. The in-situ monitoring of optical and electrical properties allowed us to distinguish fine modifications of $\mathrm{Al}$ film nanostructure. We were able to determine the growth mode in real-time and to estimate the percolation threshold of the growing aluminum layer. We found different optical, electrical and microstructural properties of the ultrathin aluminum films of equivalent mass thickness $\sim 4.5 \mathrm{~nm}$ prepared at deposition rates of $0.45 \mathrm{~nm} \mathrm{~s}^{-1}$ and $0.12 \mathrm{~nm} \mathrm{~s}^{-1}$, at RF power of 200 and $50 \mathrm{~W}$, respectively. The position of the localized plasmon peak in the film grown at RF power of $50 \mathrm{~W}$ was shifted more into the UV spectral range, and a considerably nonlinear shape of I-V curves, compared to the film prepared at RF power of $200 \mathrm{~W}$, was obtained. The lower deposition rate resulted in semicontinuous film morphology with well pronounced nanoparticulates of dimension around $50 \mathrm{~nm}$. Our experiments demonstrated that the nanostructure of aluminum ultrathin film can be simply controlled by variation of the RF power.

\section{Acknowledgments}

The research was supported by the Czech Science Foundation, project GP202/09/P324 and the Grant Agency of the Academy of Sciences of the Czech Republic, projects: AVOZ 10100522, IAA100100718, and IAA100100729. The authors thank VAKUUM Praha for support of this research. We are also indebted to Dr. Chvostova and Dr. Slechtova for film thickness measurements.

\section{References}

1. I. Gryczynski, J. Malicka, Z. Gryczynski, K. Nowaczyk, and J. R. Lakowicz, "Ultraviolet surface plasmon-coupled emission using thin aluminum films," Anal. Chem. 76, 4076-4081 (2004).

2. K. Ray, M. H. Chowdhury, and J. R. Lakowicz, "Aluminum nanostructured films as substrates for enhanced fluorescence in the ultraviolet-blue spectral region," Anal. Chem. 79, 6480-6487 (2007). 
3. M. H. Chowdhury, K. Ray, and J. R. Lakowicz, "Use of aluminum films as substrates for enhanced fluorescence in the ultraviolet-blue spectral region," Proc. SPIE 6869, 68690E (2008).

4. J. J. G. P. Loo, "Nucleation and growth of PVD aluminum," Nat. Lab. Unclassified Report Philips Electronics N.V., Vol. 807/98 (1998).

5. H. Du, J. Gong, C. Sun, S. W. Lee, and L. S. Wen," Carrier density anddc conductivity of ultrathin aluminum films," J. Mater. Sci. 39, 2865-2867 (2004).

6. H. Du, J. Q. Xiao, Y. S. Zou, T. G. Wang, J. Gong, C. Sun, and L. S. Wen," Optical properties of ultrathin aluminum films deposited by magnetron sputtering in visible band," Opt. Mater. 28, 944-949 (2006).

7. H. V. Nguyen, I. An, and R. W. Collins, "Evolution of the optical functions of aluminum films during nucleation and growth determined by real-time spectroscopic ellipsometry," Phys. Rev. Lett. 68, 994-997 (1992).

8. R. C. Weast, Handbook of Chemistry and Physics, 1974-1975, 55th ed., CRC Press, Cleveland, OH (1974).

9. I. M. Rycroft, and B. L. Evans, "The in situ characterization of metal film resistance during deposition," Thin Solid Films 290-291, 283-288 (1996).

10. J. Bulir, M. Novotny, P. Pokorny, J. Lancok, J. Musil, and J. Nahlik, "High rate reactive magnetron sputtering of alumina coatings," E-MRS Spring Meeting Proc. E-MRS Spring Meeting, Strasbourg, France 6-18 (2009).

11. P. Pokorny, M. Novotny, J. Bulir, J. Lancok, M. Misina, and J. Musil, "Study of processes in a pulsed magnetron $\mathrm{Ar} / \mathrm{O} 2$ plasma by mass spectrometry," Proc. 35th EPS Conference on Plasma Phys. ECA, Vol. 32, 5.142 (2008).

12. P. Pokorny, J. Bulir, J. Lancok, J. Musil, and M. Novotny, "Generation of positive and negative oxygen ions in magnetron discharge during reactive sputtering of alumina," Plasma Process. Polym. 7, 910-914 (2010).

13. M. Novotny, J. Bulir, P. Pokorny, J. Bocan, P. Fitl, J. Lancok, and J. Musil, "Optical emission and mass spectroscopy of plasma processes in reactive dc pulsed magnetron sputtering of aluminum oxide," J. Optoelectron. Adv. Mater. 12, 697-70 (2010).

14. H. Kersten, G. M. W. Kroesen, and R. Hippler, "On the energy influx to the substrate during sputter deposition of thin aluminum films," Thin Solid Films 332, 282-289 (1998).

15. T. Mehdi, P. B. Legrand, J. P. Dauchot, M. Wautelet, and M. Hecq, "Optical emission diagnostics of an rf magnetron sputtering discharge," Spectrochim Acta B 48, 1023-1033 (1993).

16. H. G. Tompkins and E. A. Irene, Handbook of ellipsometry, William Andrew, Inc., Norwich NY (2005).

17. B. Johs and J. S. Hale, "Dielectric function representation by B-splines," Phys. Status Solid A 205, 715-719 (2008).

18. A. F. Mayadas and M. Shazkes, "Electrical-resistivity model for polycrystalline films: the case of arbitrary reflection at external surfaces," Phys. Rev. B 1, 1382-1389 (1970).

Biographies and photographs of the authors not available. 